https://doi.org/10.52449/1857-4114.2020.36-2.03

CZU: 796.015:33

\title{
TRAINING OF ENTREPRENEURIAL SKILLS FOR PERFORMANCE SPORTSMEN FOR THE DEVELOPMENT OF THE BUSINESS ENVIRONMENT IN THE REPUBLIC OF MOLDOVA (ASCERTAINING FRAMEWORK)
}

\author{
Popa Ghenadie ${ }^{1}$, ORCID: 0000-0003-0339-1871 \\ Dorgan Viorel', ORCID: 0000-0002-4649-4734 \\ Amelicichin Ecaterina ${ }^{3}$, ORCID: 0000-0002-5032-9424 \\ ${ }^{1,2,3}$ State University of Physical Education and Sport, Chisinau, Republic of Moldova
}

\begin{abstract}
In order for the sports field to be in permanent development, it is considered particularly necessary to weaken a sports-professional continuity, which should reflect the manifestation of the volume of skills of performance athletes in the subsequent activity, after completing their career. They certainly know in detail the specifics of multi-annual training, strategies, technologies, training methodologies and, obviously, are considered the right people to become entrepreneurs in sports activities, thus promoting the field. This article describes some innovative ways that can be the basis for training entrepreneurial skills in performance athletes for business development in the Republic of Moldova. The study is focused on reporting the opinions of many specialists in the field, performance athletes, and obviously on the author's research, all aimed at establishing a special course of lessons in the reference discipline, which will provide the most eloquent information in the sense of high professional training to entrepreneurship.

Keywords: skills, business environment, performance athletes, entrepreneurship, continuity, ascertainment, training program.
\end{abstract}

\section{Actuality}

The study on the methodology of skills training for entrepreneurship in sports is conditioned by the concept of development and promotion of entrepreneurship with an innovative character for performance athletes, towards the end of sports careers [2, 3, 4, 7]. This desideratum imposed the establishment of objectives, directions and ways of developing the entrepreneurial phenomenon, as well as the determination of the principles and implementation mechanisms in order to ensure favorable conditions for the professional training of performance athletes to entrepreneurial activities in small and medium innovation business in the Republic of Moldova.
The concept of innovation entrepreneurship in Moldova corresponds to the priorities of long-term socio-economic development, reflected in the Government of the Republic of Moldova's Program "European Integration: Freedom, Democracy, Welfare" [2, $5,6]$.

At the same time, it is worth mentioning that in recent years in the Republic of Moldova $[3,7,8]$ there has been a tendency to reduce the number of sports venues: sports fields, stadiums, sports halls, swimming pools, etc. In the new economic conditions, maintaining sports venues in a satisfactory condition has become a difficult problem. Thus, it becomes necessary to develop the sports infrastructure, which can be the object of creating the conditions for consolidating the partnerships 
between science and business, as well as for intensifying the business activity in the Republic of Moldova.

To the development of the national business environment, an essential contribution can be brought by the performance athletes after the end of the competitive activity by opening some businesses in the field, having as final results the construction of some sports venues. Obviously, sports venues, where daily training and competitions are held, must be provided with a respective infrastructure, including: medical office, massage room, physiotherapy room, bathroom, hydrotherapy room with showers and baths, sauna, gym, oxygenation and aero-ionization room, relaxation room with music, place for reading, rehydration, "vitaminization", etc. It is also necessary to provide rooms for teachers, coaches, instructors, referees, warehouses for sports equipment, inventory and other materials $[4,5$, 7].

In this context, the creation of such constructions can certainly contribute to the development of the business environment in our country and to an increase in the interest and quality of

The Aim of the study. The pedagogical research aimed at determining the innovative ways of training entrepreneurial skills in performance athletes for business development in the Republic of Moldova by developing new training programs, in which to participate the entire management elite in domestic sport by innervating them (a specialists-managers of the field and, obviously of performance athletes), the subjects being selected from the perspective of the requirements of knowledge of the business environment in the field of sports in particular and of social development in our country in general.

The Objectives of the study. This study had a ascertaining character, respectively the actions were focused on achieving the following objectives:
- researching the objectives of entrepreneurial and innovative activity in performance athletes, identifying methods and mechanisms to achieve these objectives, in accordance with the principles of development of the Republic of Moldova society;

- elaboration and application of a relevant scientific research questionnaire in the context of the studied topic, where the questions formulated were with reference to different policy documents, the potential in the country (values, traditions, resources), realities, requirements and challenges of the global economy competitiveness, competence and development capabilities;

- processing the results of the opinion poll in order to obtain the respondents' opinions on the issues of interest on the basis of which it will be possible to concretize the general plan of activity of the basic experimental research;

- establishing the frame of reference on the competencies for designing the training process of performance athletes who, at the end of their sports career, will choose to achieve their own vision on entrepreneurship in order to start a business;

- elaboration of a model / system of the content of entrepreneurial and innovative competencies characteristic of the entrepreneurial activity in the field of sport, which, subsequently to be proposed to athletes I students within the academic-instructive academic process by initiating, organizing and conducting a special course.

The relevant scientific methods used in the research are: the method of studying the specialized literature; pedagogical observation; questionnaire survey method; measurement and evaluation method; statistical-mathematical methods; graphical and tabular method.

The study of the specialized literature was to create the possibility of documentation regarding the opinions of specialists on the main research activities in the field of sports and innovation entrepreneurship, of the consolidation of the business environment in the Republic of Moldova. 
The pedagogical observations allowed to obtain complex information, which had the advantage of reproducing the natural, effective behavior of sports consumers.

The main element of the study: the questionnaire survey method aimed at accumulating data on the motivation to learn of future specialists in the field for entrepreneurship. The content of the sociological questionnaires developed and applied during our research were formulated in accordance with the purpose of the research and the established objectives. Their structure and content for each study followed a logical scheme, including both general and specific questions. Before being applied to the categories of respondents, the questionnaires were validated through an instrumental research (pilot survey) conducted on a certain number of people.

The study was conducted by questioning two groups of respondents: one with senior managers from national sports organizations (private sports clubs and national sports federations), respectively 59 people, and the second, with performance athletes pursuing sports careers and others already at the end of it (43 athletes from various Olympic events). The results of the interviews were analyzed and interpreted in the scientific laboratory of the Department of Physical Culture
Management, Faculty of Pedagogy, SUPES, Chisinau.

The group discussions focused on the following main topics:

- organizing the entrepreneurship process;

- improving professional training, communication and motivation of graduates / athletes from sports entities;

- the objectives and elements highlighted by starting a business in the field of physical culture;

- the communication tools used and the influence of their use on the development of the business environment in our country.

\section{Results and discussion}

To the question "Do you know what are the factors that could influence the decision to set up a business in the field of physical culture", most categories of respondents mentioned that among them are: increased influence on entrepreneurship education and studies (24\%), age, work experience and sports career (29\%), etc.; entrepreneurial environmental factors: economy, sources of financing, consultative assistance, support staff, legal conditions and business organization in the field $(22 \%)$; poor knowledge in the field of entrepreneurship (25\%), especially in terms of location, market sector, skills required for the selected field of activity, etc.

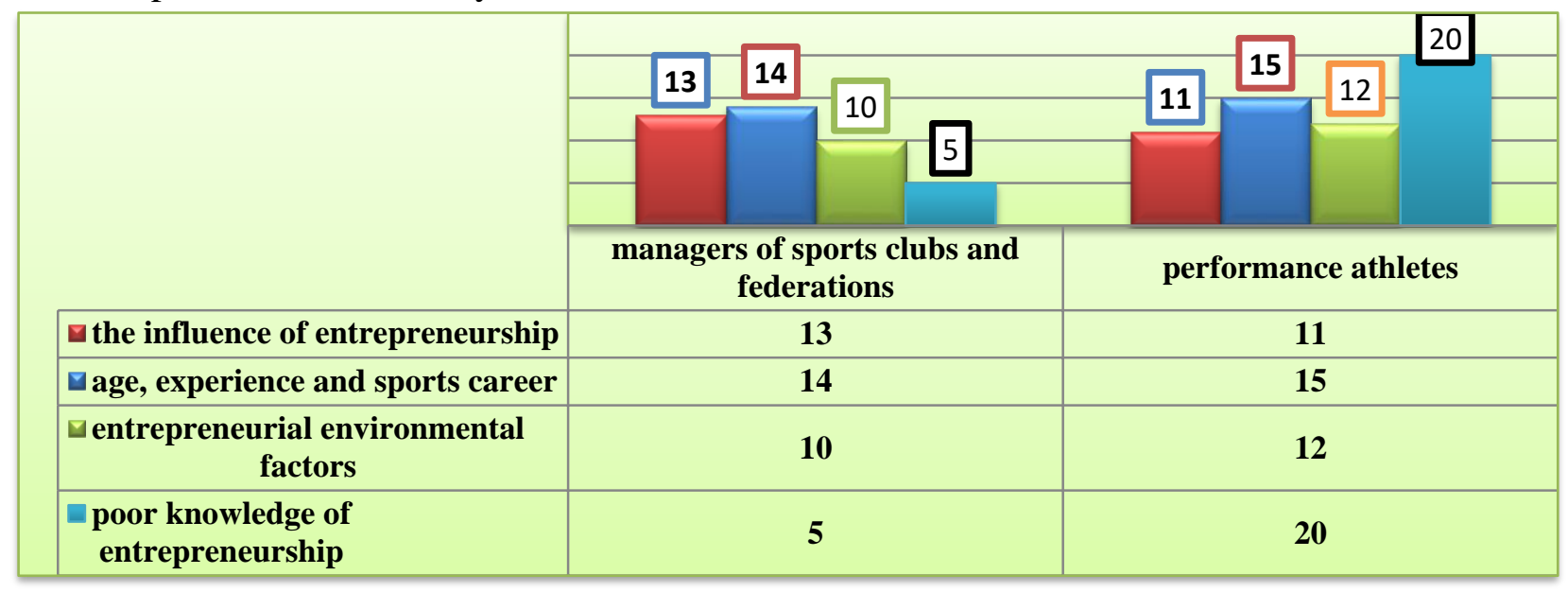

Fig. 1. Answers on the factors that could influence the decision to set up a business in the field of physical culture 
Regarding the answers to the question "Do you think you have your own opportunities and resources to start a business in the field of physical culture?" (Figure 2), most categories of respondents stated that in general resources are not always sufficient (57\%), do not have financial possibilities $(32 \%)$ to open a business, and $11 \%$ mentioned that they have these possibilities. Regarding the percentage of $57 \%$, managers and performance athletes probably consider that they are not enough mainly due to the reporting of possibilities and real resources to possible benefits. They also said that financing the business idea is a central issue, often constituting a serious barrier to development.

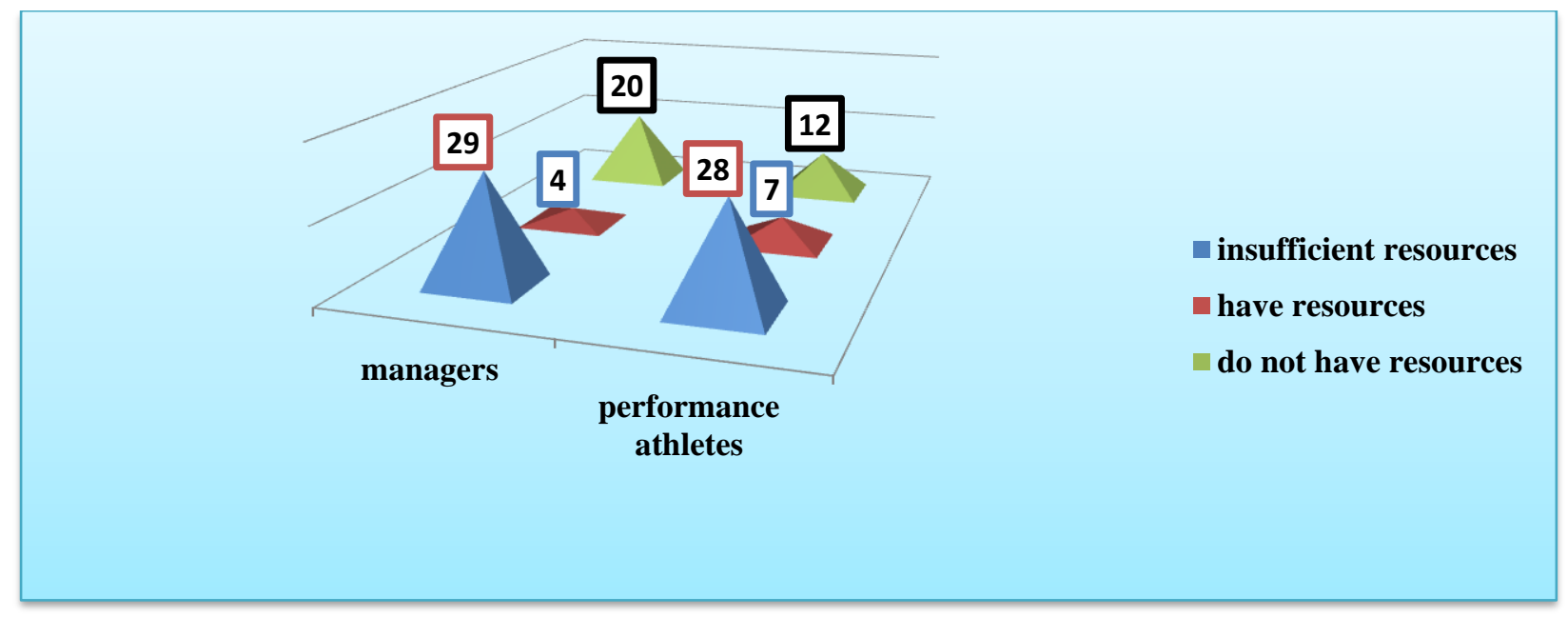

Fig. 2. Answers on the possibilities and resources needed to open a business in the field of physical culture

Regarding the question "Do you know what are the stages of identifying a successful business?" (Figure 3). The respondents mentioned in a percentage of $33 \%$ that they do not know, in a percentage of $28 \%$ they specified that innovation and creativity are important qualities in finding a successful business in the field, $18 \%$ gave affirmative answers to this question, and $21 \%$ found it difficult to answer this question.

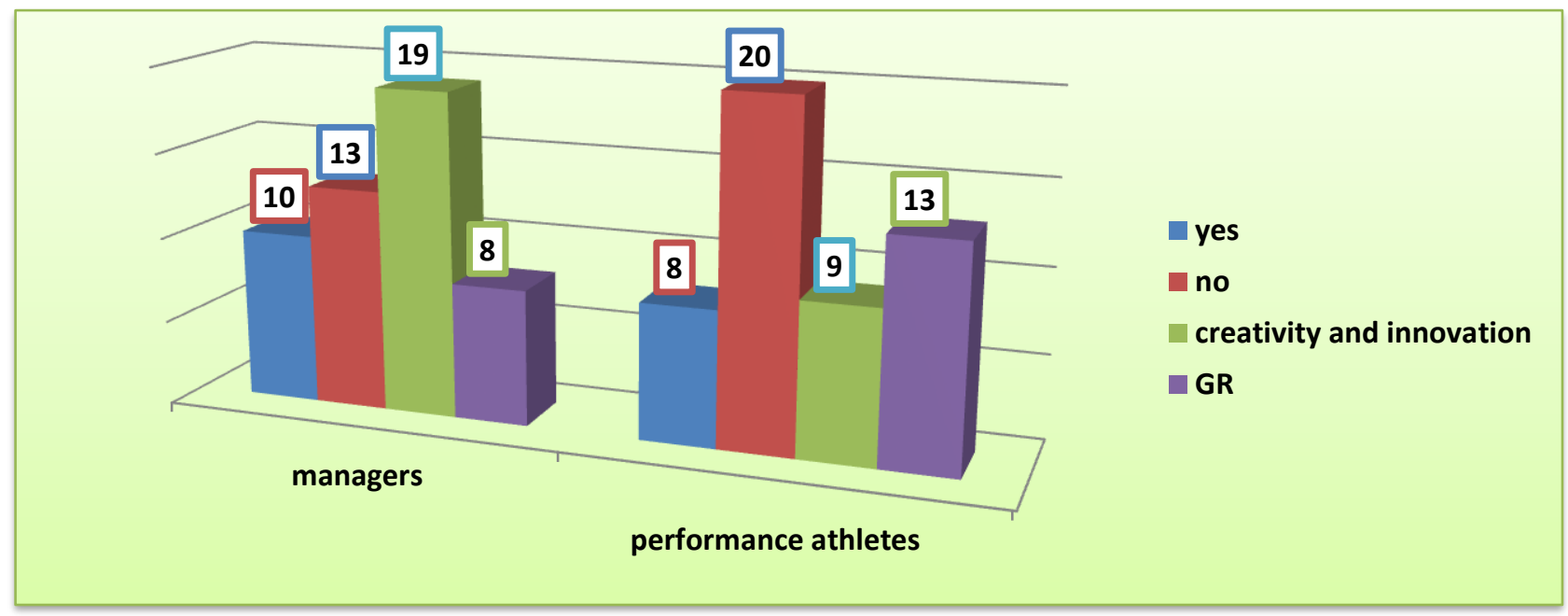

Fig. 3. Answers about the stages of a successful business 
Regarding the question "Can you mention which of the listed reasons contributes to determining the initiation of a business in the field?", $31 \%$ mentioned that their personal interests and desires determine them to start a business in the field; $11 \%$ family and relatives, $35 \%$ social relations and society, and a percentage of $23 \%$ specified that personal and professional development.

To the question "Can you mention which of the listed qualities can constitute the profile of the successful entrepreneur in the field of physical culture?", from the accumulated answers it can be seen that talent and clairvoyance are very important qualities (24\%); intuition (26\%); charisma and leadership qualities (12\%); independent character (29\%); availability of financial resources and the existence of a business plan (9\%).

Regarding the question "Have you ever thought of your career as a business?", the respondents gave positive answers in a significant percentage, respectively of $68 \%$, negative answers in a percentage of $7 \%$, and a percentage of $25 \%$ they mentioned that they rarely balanced their personal career with business.

To the question "Do you know the correct meaning of the concepts of entrepreneur and entrepreneurship?", most categories of respondents mentioned that they generally know it (37\%), but would like to improve their knowledge in this field (42\%), 21\% do not know the correct meaning of these concepts.

\section{Innovative elements of the study}

Based on the research team's own initiative and, taking into account these results, as well as other factors that may be able to propel the entrepreneurial phenomenon in favor of the future sports specialist, all contributed to the development of the skills complex considered necessary for the professional training of future entrepreneurs for the business environment in the Republic of Moldova.

Table 1 reflects the general competencies to be acquired by the applicant by studying this discipline, and Table 2 the specific competencies.

\section{Table 1. General competencies}

\begin{tabular}{|l|}
\hline General competencies \\
\hline 1. The use of specialized language in communication relationships. \\
2. Valorization of information, methods and means specific to the study discipline. \\
3. The use of knowledge, methods and means specific to the study discipline, in order to \\
develop the entrepreneurial capacity. \\
4. Applying the system of specific rules to the organization and practice of entrepreneurial \\
activities and adopting an appropriate behavior in interpersonal and group relationships. \\
5. Capitalizing on scientific research in the field of entrepreneurship in accordance with the \\
objectives set, with the issue of investigation, with the data collected and analyzed, and last \\
but not least the shaping of solutions.
\end{tabular}

Below are presented the specific competencies, contents and learning activities that will underline the elaboration of the curriculum of the discipline that will support the respective courses. Thus, the following competencies that the student must acquire can be provided. The student will be competent: to define the concept of business, profit and entrepreneur; to present the specifics of the entrepreneurial activity; to present the character traits of the entrepreneurs; to concretize which are the factors that determine and influence the entrepreneurial behavior; develop an action plan for a sports business; to specify the importance of innovative entrepreneurship. 


\section{Table 2. Specific competencies}

\begin{tabular}{|c|c|}
\hline Professional skills & $\begin{array}{l}>\text { Skills for documenting and developing business action plans } \\
\text { in sports in accordance with funding sources. } \\
\text { entrepreneurial activity. } \\
\text { e Procedural, legal knowledge regarding the acts of setting up a } \\
\text { sports organization and its registration with the competent bodies. } \\
>\text { Mastering the different techniques of interpreting the } \\
\text { legislation that regulates the entrepreneurial activity in the field. }\end{array}$ \\
\hline Transversal skills & $\begin{array}{l}>\text { Integrated approach to knowledge about entrepreneurship and } \\
\text { deepening interdisciplinary scientific research procedures. } \\
\text { Knowledge of working methods in the field of developing a } \\
\text { business plan. } \\
>\text { Training the skills necessary for multidisciplinary } \\
\text { cooperation, communication and building partnerships based on the } \\
\text { application of acquired knowledge and the development of } \\
\text { transdisciplinary scientific reasoning. }\end{array}$ \\
\hline
\end{tabular}

Also, the student will be competent: to mention which are the legal institutions that monitor the legal functioning of entrepreneurship in the Republic of Moldova; to identify and present the defining elements of the external environment of sports entities that provide them with basic, legal and economic information; to present and define the main legal forms of organizing a sports business; to identify and interpret the legal framework for the organization and development of private business activity; to elaborate the reorganization plans of the sports entity.

Alternatively, the student will be competent: to define and understand the concepts of law, sports law, social relationship, legal relationship, legal person, natural person; to accumulate knowledge regarding the patrimony, facts and legal acts; to know, apply and interpret the legislation on entrepreneurship in the Republic of Moldova; to know the law on physical culture and sports, including other normative acts that regulate the sports field.

Both these results and a number of other requirements will represent the discipline called:
"Entrepreneurship, elements of law and application of sports legislation in sports activity", proposed to be taught to first year students, from the reference specialization.

\section{Conclusions}

$\checkmark$ This study determined the need to develop and apply the sociological questionnaire with specialists in sports and performance athletes, whose opinions can be taken into account and can contribute to the establishment and development of content in the discipline "Entrepreneurship, elements of law and application of sports legislation in sports activity ", which should contribute, in turn, to the formation of theoretical / practical knowledge in accordance with the need to acquire professional, entrepreneurial and innovation skills required by the specialist in the field.

$\checkmark$ The opinions of the respondents largely coincided with the own proposals of the research team, and the reasons underlying the initiation of such a discipline is inconceivable.

$\checkmark$ Studying the material included in the study topic, as well as evaluating the students' results will provide the opportunity to know the degree of teaching tasks, to achieve the objectives of entrepreneurship, having positive 
effects on employment, making the phenomenon of entrepreneurship have continuity.

Argument. As an argument to describe the results of this study, it can be mentioned that the innovative ideas and elaborations, clarifications and wishes presented on the subject of entrepreneurship, being transposed into the practice of professional training of future sports specialists will provide students the opportunity to acquire a rich activity and research experience in the field of entrepreneurship and sports management, which will ensure the acquisition of skills and competencies for an effective professional career as an entrepreneur or manager in the relevant institutions.

\section{References:}

1. Apostu A. (2010). Imbunătăţirea managementului competiţiei sportive. Rezumat al tezei de doctor. Cluj Napoca, p. 4-6.

2. Budevici-Puiu L., Manolachi V. (2016). Management şi legislaţie în educaţia fizică şi sport. Chişinău: USEFS, p. 3-20.

3. Budevici A. (2000). Management în educaţie fizică şi sport. Iaşi, p. 11-19.

4. Budevici A. (2004). Filosofia sportului şi a activităţilor de loisir. Iaşi: Universitatea „A.I.Cuza”, Facultatea de Educaţie Fizică şi Sport, p.8-11.

5. Budevici L. (2012). Legislaţie sportivă naţională şi internaţională. Chişinău: Editura Valinex. 159 p.

6. Daft R. L. (2012). Management. Thompson Education, p. 34.

7. Manolachi V. (2016). Managementul şi dezvoltarea durabilă a sportului. Chişinău: USEFS, p. 29-48.

8. Voicu A. (1998). Managementul organizaţiilor şi activităţii sportive. Cluj-Napoca: Ed. Risoprint. 247 p. 